\title{
Quarter car model optimization of active suspension system using fuzzy PID and linear quadratic regulator controllers
}

\author{
Abdussalam Ali Ahmed * \\ Mechanical and Industrial Engineering Department, Bani Waleed University, Bani Waleed, Libya.
}

Global Journal of Engineering and Technology Advances, 2021, 06(03), 088-097

Publication history: Received on 01 February 2021; revised on 04 March 2021; accepted on 06 March 2021

Article DOI: https://doi.org/10.30574/gjeta.2021.6.3.0041

\begin{abstract}
The primary objective of this paper is to improve the performance of a car's active suspension system and control the vibrations that occurred in the car's using two well-known control technologies, namely the Linear Quadratic Regulator (LQR) and fuzzy PID control. When the car suspension is designed, a quarter car model with two degrees of freedom is used. A complete control system is needed to provide the desired suspension performance and characteristics such as passenger comfort, road handling, and suspension deflection, this control system performed using the MATLAB/SIMULINK and includes three parts: input signals (actuator force and road profile), Controller part, and the suspension system model. The simulation results from the implemented Simulink models show a comparison between the uncontrolled suspension system and the suspension system with a fuzzy PID controller and the active suspension system of the car based on the linear-quadratic regulator, and it is explained thoroughly.
\end{abstract}

Keywords: Active Suspension; Quarter Car Model; Linear Quadratic Regulator; Fuzzy PID Control.

\section{Introduction}

In the interest of improving the overall performance of automotive vehicles in recent years, suspensions incorporating active components have been developed and the process moves to further developments and improvements.

The automotive suspension on a vehicle typically has the following basic tasks [2]: 1) To isolate a car body from road disturbances in order to provide good ride quality, 2) To keep good road holding, 3) To provide good handling, 4) To support the vehicle static weight.

Car suspension systems are classified into three main types, namely passive, semi-active, and active suspension systems. In the passive suspension, a spring and the suspension system parts are placed between the car body wheels. They allow the forward compensation between driving comfort and the suspension stroke deviation. According to the chassis features, the suspension stroke is limited to some specific values. The ride comfort is reduced when the suspension deviation reaches these specified limited values [3].

In the active suspension system, a force actuator controlled by the feedback controller is placed between the car body. A controlled suspension system permits forward compensation between the riding comfort and the performance criteria of the suspension deviations [4-5].

Researchers recently conducted many studies and worked on the active suspension of the vehicle to achieve a good performance of the active suspension system, thus improving both road handling and ride comfort. To date, many

\footnotetext{
* Corresponding author: Abdussalam Ali Ahmed

Mechanical and Industrial Engineering Department, Bani Waleed University, Bani Waleed/Libya.
} 
control methods such as Linear Quadratic Regulator (LQR) [6], Single-Network Approximate Dynamic Programming [7], higher-order sliding mode control [8], Ho Method [9] Fuzzy Logic [10], And the neural network method [11] were used in the active car suspension field. The performance of the active suspension system in cars can be improved by several control technologies. However, these methods require a specific performance decision schedule or complex learning mechanism, and some application difficulties.

In this paper, the performance of the active suspension system of the car has been compared using two different control strategies, the first strategy is using of the Linear Quadratic Regulator Control Method and the second is the using of Fuzzy PID Controller, this comparison will show a good contribution to the field of suspension systems.

This work is arranged as follows: Section 2 which is devoted to the mathematical model of the car suspension system in addition to the road profile used in this paper. This section also presents an open-loop Simulink model of an active suspension system. Section 3 introduces the control strategy and gives a brief explanation about the Fuzzy PID controller and the linear quadrature regulator approach. Section 4 covers some simulations for comparing a closedloop Simulink car suspension system using the two controllers. Section 5 gives the results and discussion of this work and section 6 of this paper presents the conclusion of the performed work.

\section{Mathematical Model}

The 2-DOF quarter car model and the physical parameters used in this paper are shown in Figure 1 and Table 1 respectively, this model is one of the most widely used suspension models, which is very important when studying vehicle dynamics especially ride comfort and road handling characteristics. It represents the vibration behavior of the car body and the wheel. The main components of the suspension system are damper $b_{s}$, springs $K_{s}$ and $K_{t}$, in addition to force actuator $F$. The value of the actuator force must be zero in the case of passive suspension systems. The symbol $m_{s}$ denotes the sprung mass, which indicates a quarter of the total car mass and the unsprung mass $m_{u}$ represents the mass of the wheel assembly system. The damping coefficient is denoted by the symbol $b_{t}$, while the vertical stiffness of the tire is denoted by the symbol $K_{t}$. The vertical displacement of the road profile, unsprung mass, sprung mass indicated by $z r, Z u$, and $Z_{s}$ respectively.

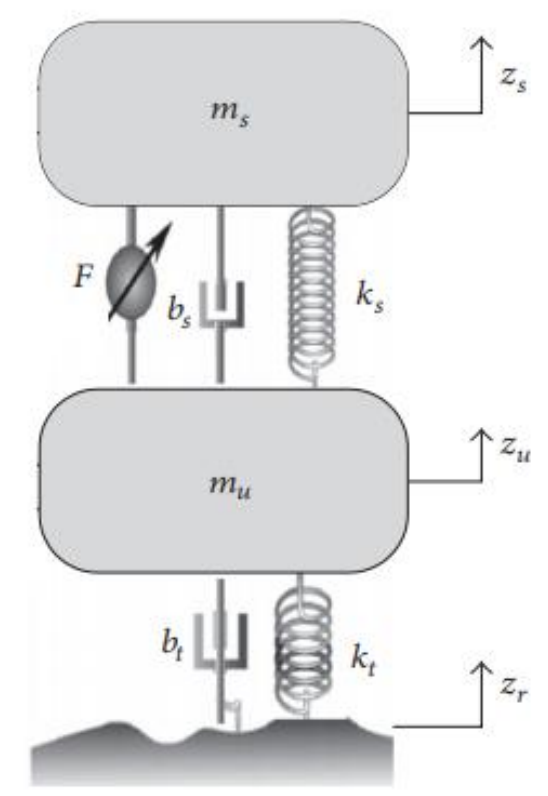

Figure 1 A quarter car model. 


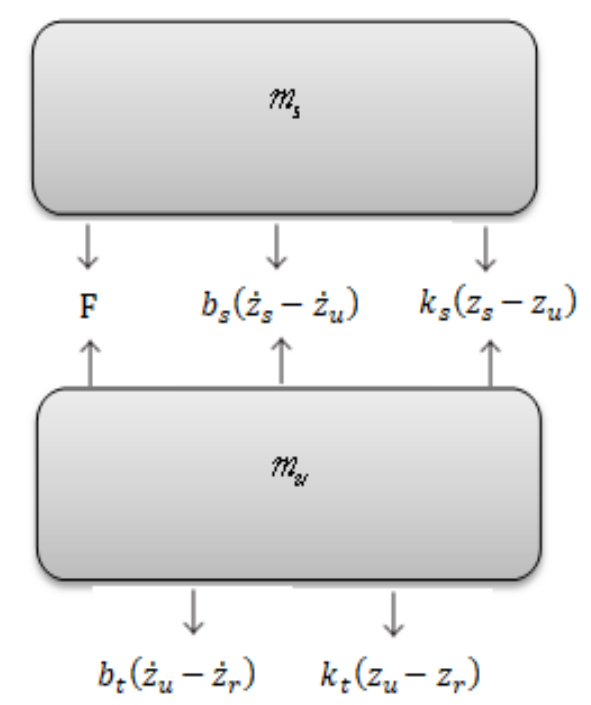

Figure 2 Free body diagram of the quarter model.

Based on the free body diagram of the quarter car model shown in figure 2 and Newton's second law, it is very easy to write the equations of motion for the system as follows:

$m_{u} \ddot{z}_{u}-b_{s}\left(\dot{z}_{s}-\dot{z}_{u}\right)-k_{s}\left(z_{s}-z_{u}\right)+b_{t}\left(\dot{z}_{u}-\dot{z}_{r}\right)+k_{t}\left(z_{u}-z_{r}\right)=-\mathrm{F}$

$m_{s} \ddot{z}_{s}+k_{s}\left(z_{s}-z_{u}\right)+b_{s}\left(\dot{z}_{s}-\dot{z}_{u}\right)=\mathrm{F}$

Where:

$z_{s}-z_{u}$ Indicates the suspension deflection, $\dot{z}_{s}$ represents the car body or the sprung mass speed (comfortable comfort indicator), $\ddot{z}_{S}$ represents the acceleration of the car body, $z_{u}-z_{r}$ represents the tire deflection (road-handling indicator), and $\dot{z}_{u}$ indicates the tire velocity.

The following data shown in the table below represents the car parameters and values used in the simulation

Table 1 A quarter car model parameters.

\begin{tabular}{|l|l|}
\hline Parameter & Value/Unit \\
\hline Sprung mass $(m s)$ & $300 \mathrm{~kg}$ \\
\hline Unsprung mass $(\mathrm{mu})$ & $59 \mathrm{~kg}$ \\
\hline Suspension system stiffness $(k s)$ & $17,000 \mathrm{~N} / \mathrm{m}$ \\
\hline The tire stiffness $(k t)$ & $180,000 \mathrm{~N} / \mathrm{m}$ \\
\hline Suspension damper $(b s)$ & $500 \mathrm{~N} . \mathrm{s} / \mathrm{m}$ \\
\hline The tire damping coefficient $(b t)$ & $1050 \mathrm{~N} . \mathrm{s} / \mathrm{m}$ \\
\hline
\end{tabular}

The figure below shows the complete Simulink model for an active suspension system, and this model was built based on equations 1 and 2 . 


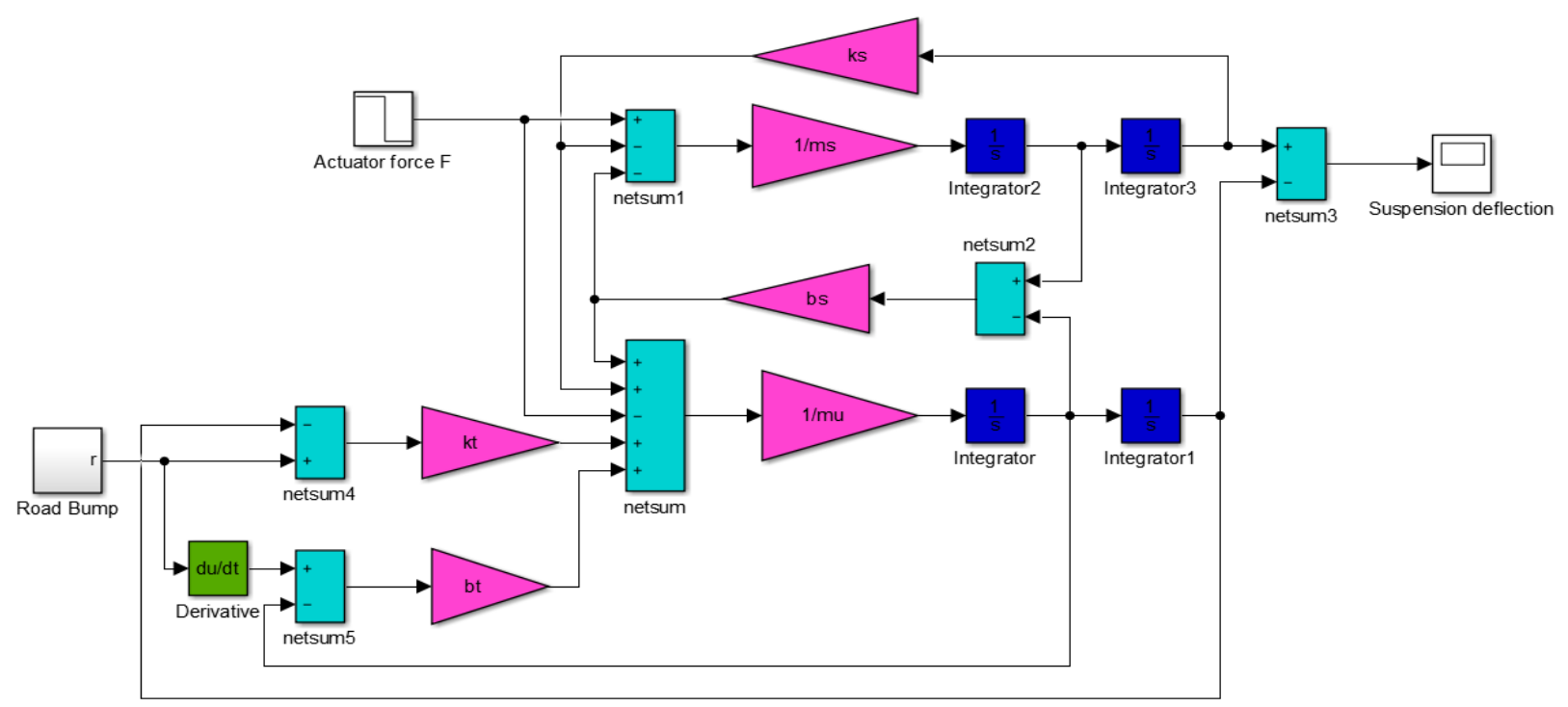

Figure 3 The Simulink model of an active suspension model.

\subsection{Road Profile}

The subsystem Simulink model of the input bump road $z_{r}$ is performed as shown in figure 4.

A single bump road input $\left(z_{r}\right)$ as shown in figure 5 is used to express the road status, conditions, and to verify the developed control system, this road bump is called road profile or road disturbance, it set to achieve a bump height of $0.05 \mathrm{~m}$.

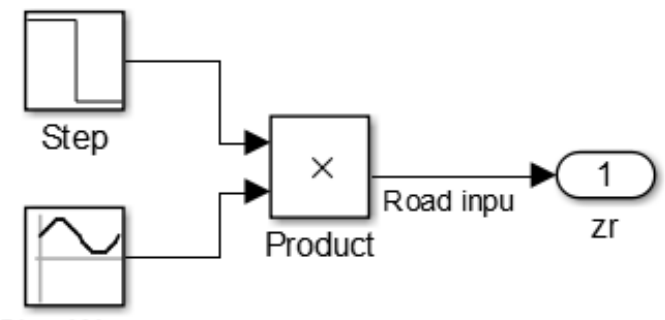

Sine Wave

Figure 4 Bumpy road input subsystem model.

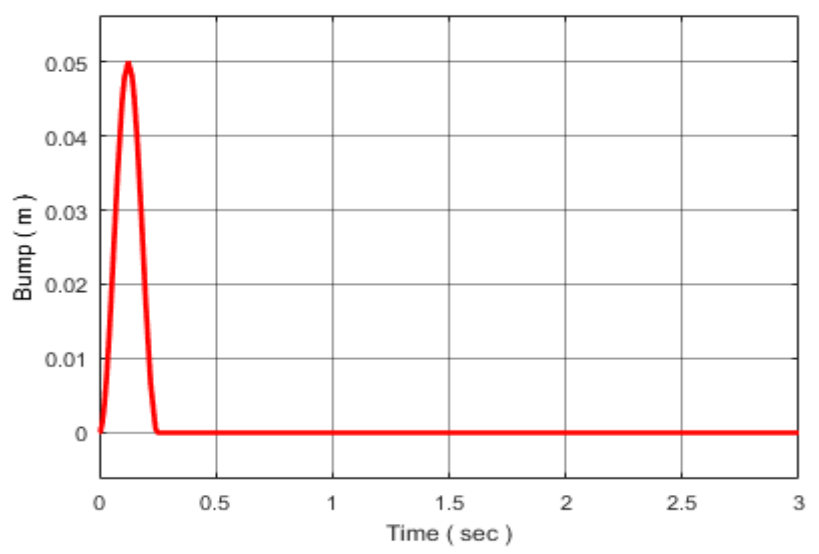

Figure 5 Bumpy road input subsystem. 


\section{Control techniques}

This part can be divided into two sections. The first section provides an overview of the two controllers used in this work, while the second section shows the Simulink model structures implemented for the active suspension system with Quadratic Regulator linear controller and fuzzy PID controller.

\subsection{Controller Design Using Linear Quadratic Regulator (LQR)}

The LQR approach to control the car suspension system is widely used in the background of many studies in the field of the car suspension system. It was used in a simple quarter car model, a half car model, as well as in a complete car model. The strength of the LQR method is that when using the performance factor index that can be weighted according to the engineers' desires and aspirations or other limitations. With this approach type, an optimal results can be achieved when factors of the performance index are taken into account [13].

The LQR method for the active suspension system has been suggested and proposed to improve passenger comfort and to get better road handling [14].

In the case of designing an LQR controller (called the gain matrix), one must optimal control vector must choose $u(t)$, so that the quadratic cost function is reduced. The mathematical formula of the quadratic cost function can be written as:

$J=\int_{0}^{\infty}\left(x(t)^{T} Q x(t)+u(t)^{T} R u(t)\right) d t$

Where,

$x$ and $\mathrm{u}$ are the state vector and the control vector respectively.

$(r \times r)$ and $(n \times n)$ are called the symmetric positive definite weighted Matrices.

The main condition of the matrices $R$ and $Q$ is must be $[R=R T \geq 0$ and $Q=Q T \geq 0]$.

The values of weighted matrix $R$ (control penalty) and (state penalty) depends on designer desires. The designer must choose the appropriate values for both of $R$ and $Q$ to find the appropriate gain matrix using MATLAB software.

The configuration of the state variable feedback is shown in the figure 6 .

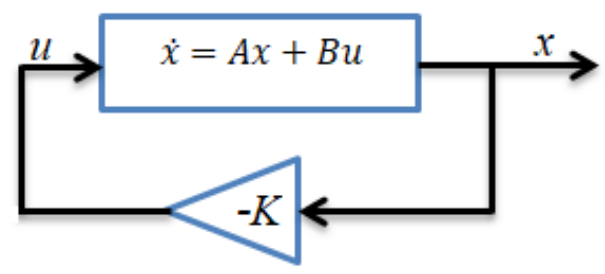

Figur 6 The configuration of the state variable feedback.

A suitable linear full-state feedback control law used as,

$(t)=-(t)$

Where K represents the state feedback gain matrix for the LQR controller, which can be defined by:

$$
K=R^{-1} B^{T} P
$$

The next Algebraic Riccati Equation (ARE) is using to estimate the matrix P.

$A^{T} P+A P+P B R^{-1} B^{T} P+Q=0$ 
By selecting the matrix $\mathrm{Q}$ as follow:

$$
Q=\left[\begin{array}{ccc}
1000 & 0 & 0 \\
0 & 1000 & 0 \\
0 & 0 & 1000
\end{array}\right]
$$

And $R=0.0001$.

Therefore, the value of gain $K$ is given by:

$K=1.0 \mathrm{e}+04 *\left[\begin{array}{llll}0.0295 & 0.3072 & -2.5105 & -0.2029\end{array}\right]$

The Simulink model for the control system includes the LQR controller is shown below in Figure 7.

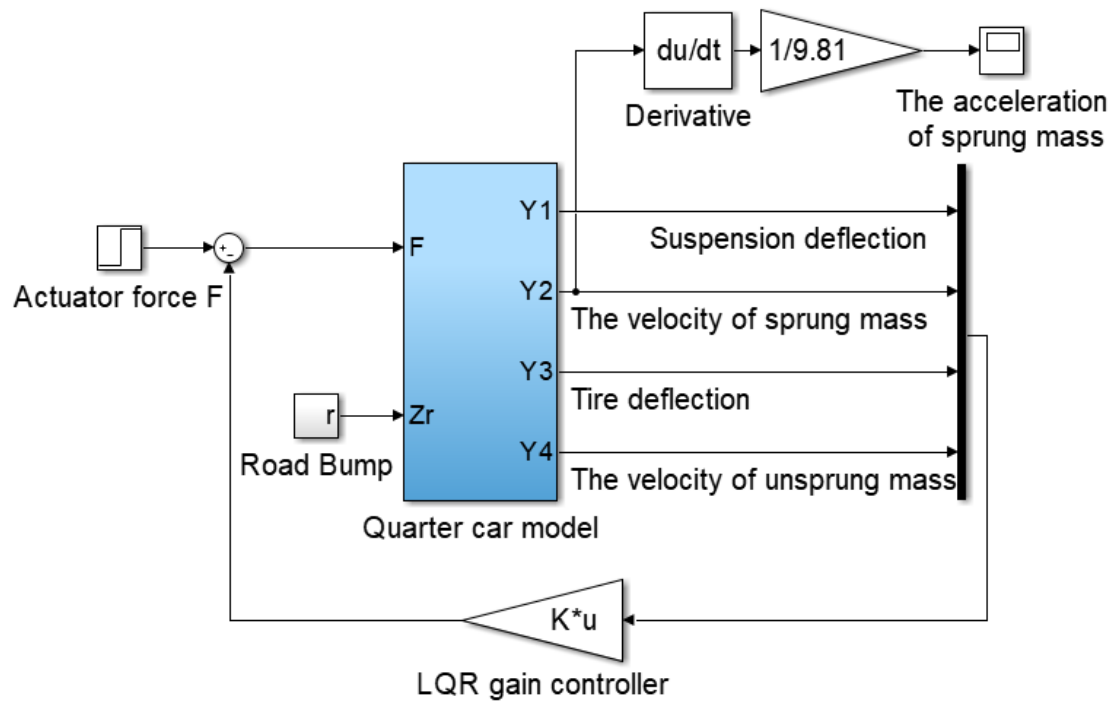

Figure 7 Simulink model for active suspension system with LQR controller.

\subsection{Fuzzy PID Controller}

The Fuzzy PID control is divided into three key components: 1: fuzzification, 2: fuzzy rules and inference, 3: defuzzification. Figure 5 displays the vehicle control system layout including a fuzzy PID controller.

The structure of the controller and the block diagram of the desired control system are implemented as shown in figures 8 and 9, which consists of the reference model, actual model of the car suspension and fuzzy PID controller.

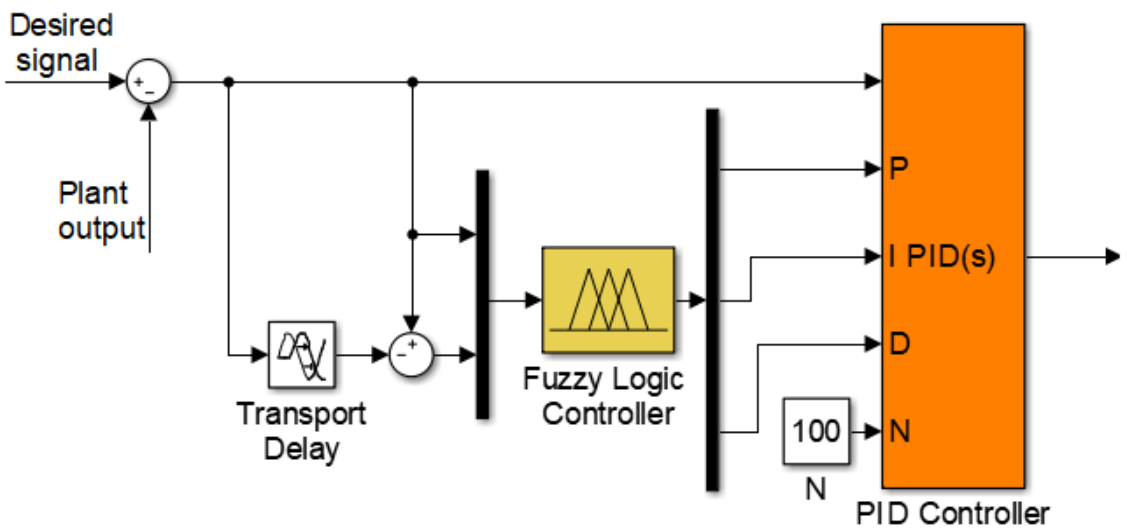

Figure 8 Fuzzy PID controller structure. 


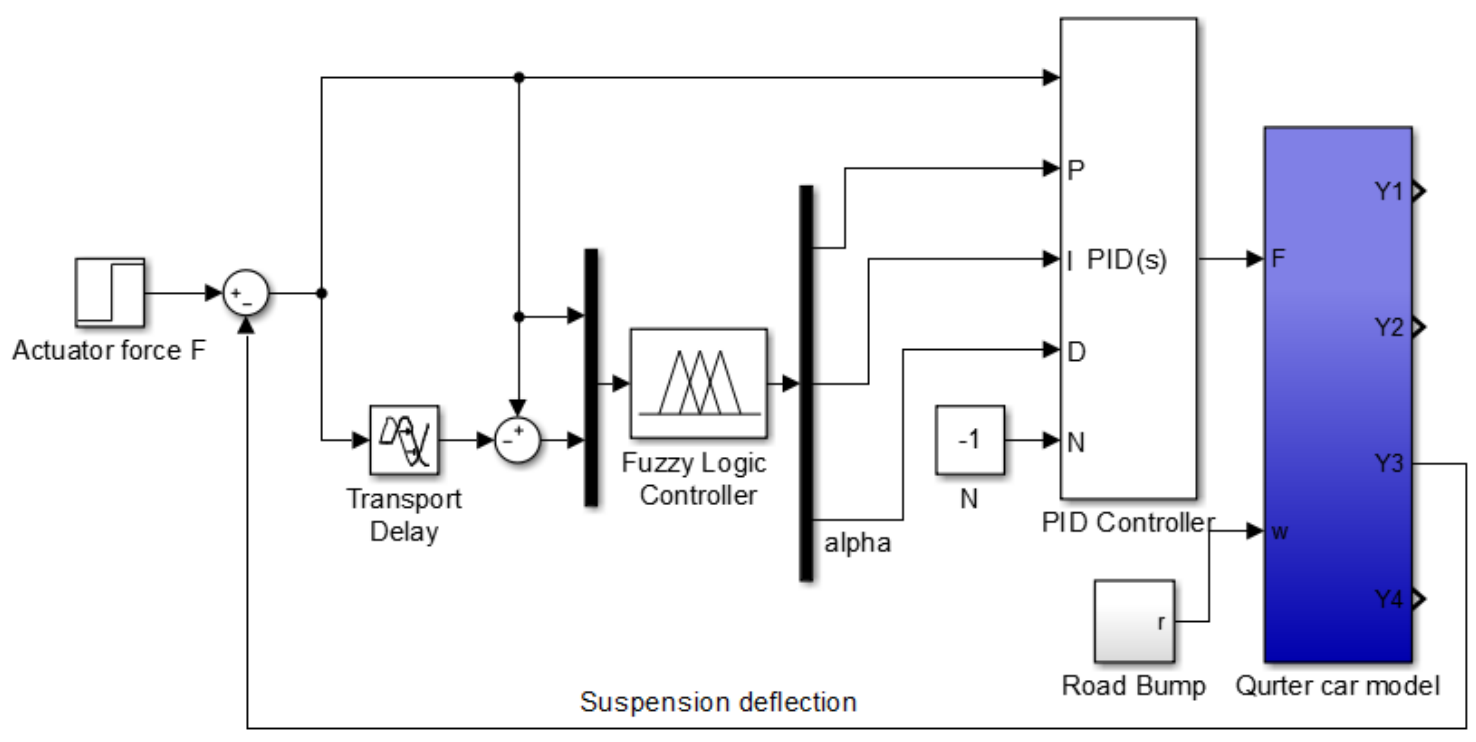

Figure 9 Simulink model for active suspension system with Fuzzy PID controller.

\section{Simulations}

Computer simulations have resulted and performed based on the equations of motion of a quarter-car model using MATLAB / SIMULINK. The performance of the car suspension system will be illustrated in terms of driving comfort, quality, and road handling, as the road bump is assumed to be the input signal of the suspension. The parameters observed are the deflection of the suspension system $\left(z_{s}-z_{u}\right)$, tire deflection $\left(z_{u}-z_{r}\right)$, sprung and unsprung mass velocities $\left(\dot{z}_{s}\right.$ and $\left.\dot{z}_{u}\right)$, and sprung mass acceleration $\left(\ddot{z}_{s}\right)$. The goal of using the LQR control method and the fuzzy PID control is to achieve a small amplitude value for suspension deflection, sprung mass acceleration, and tire deflection.

Figures (10-14) show the performance of the active suspension system for the road bump profile.

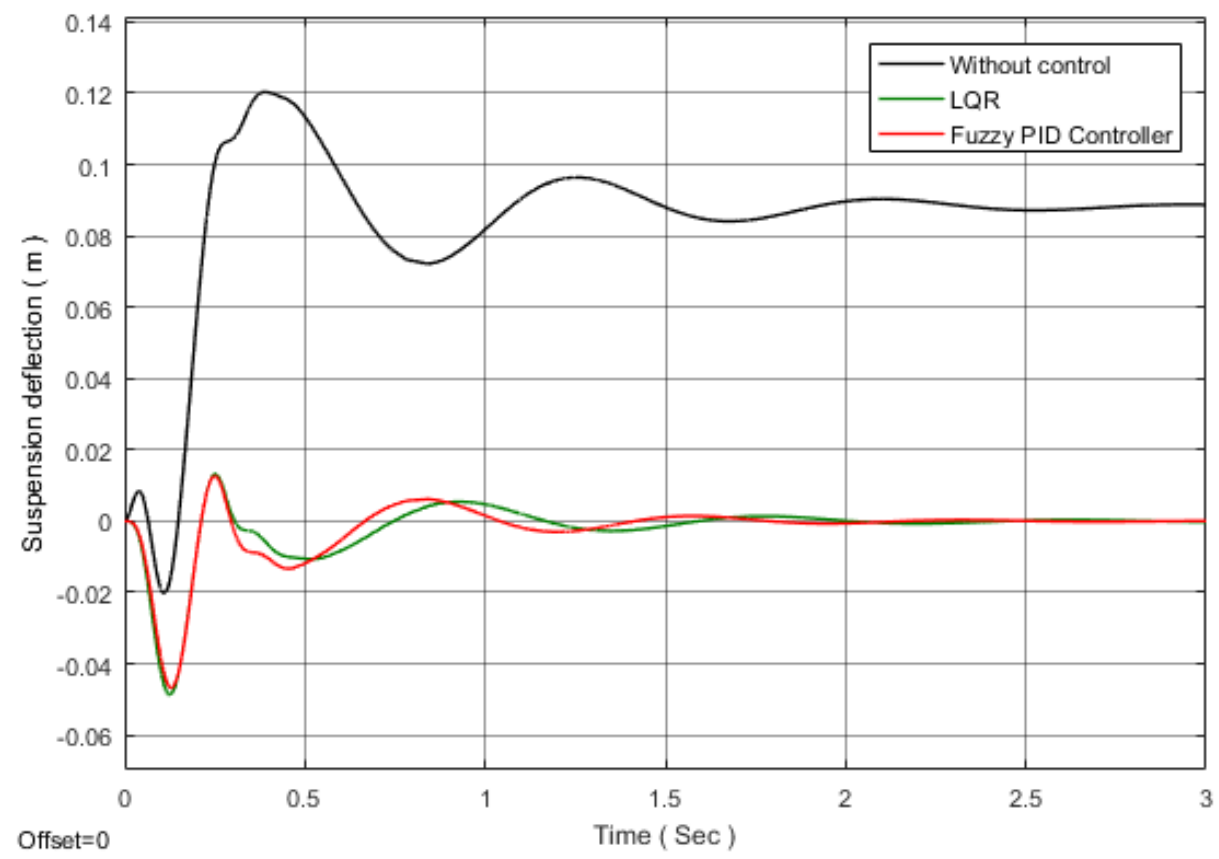

Figure 10 Suspension deflection. 
Global Journal of Engineering and Technology Advances, 2021, 06(03), 088-097

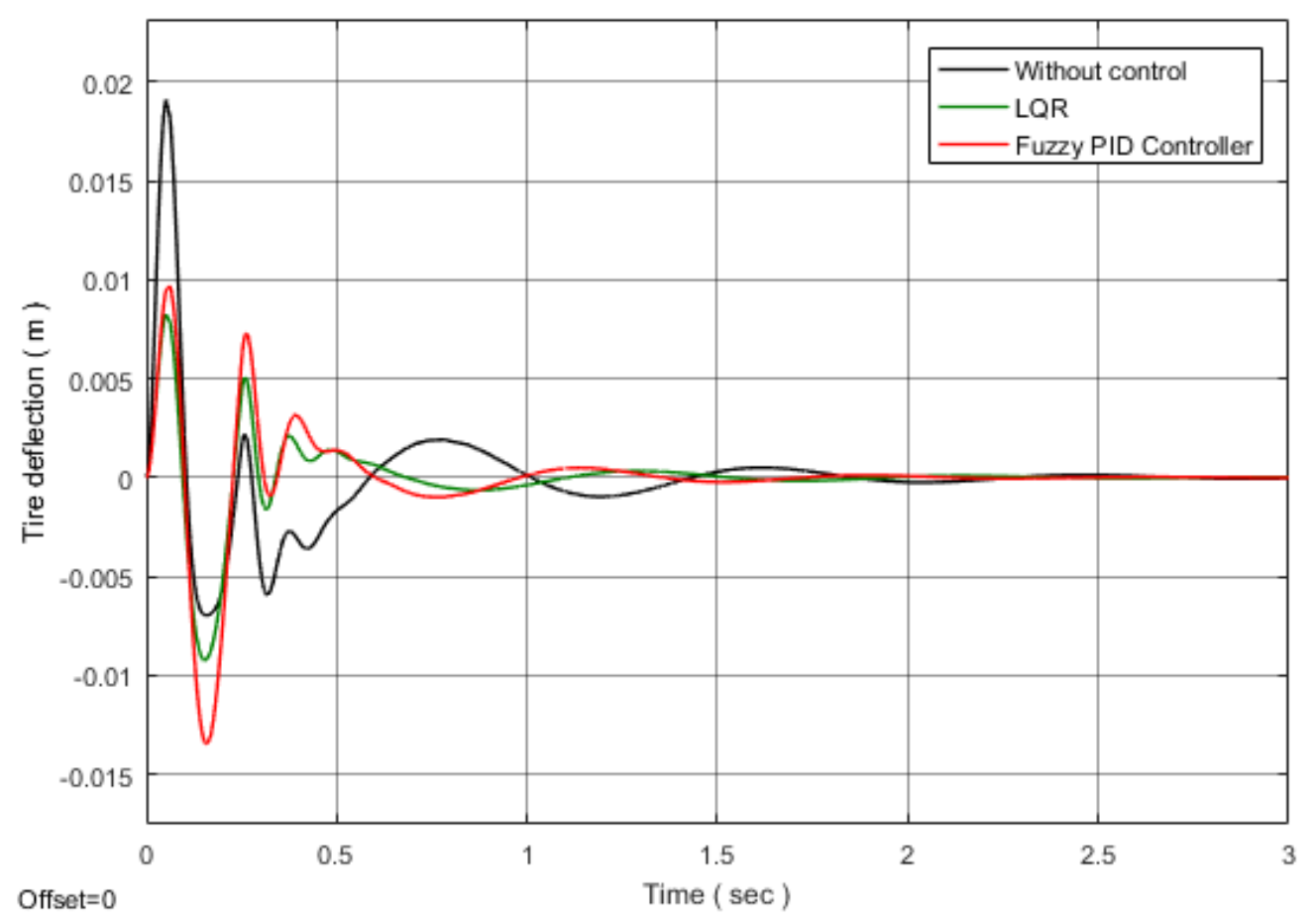

Figure 11 Tire deflection.

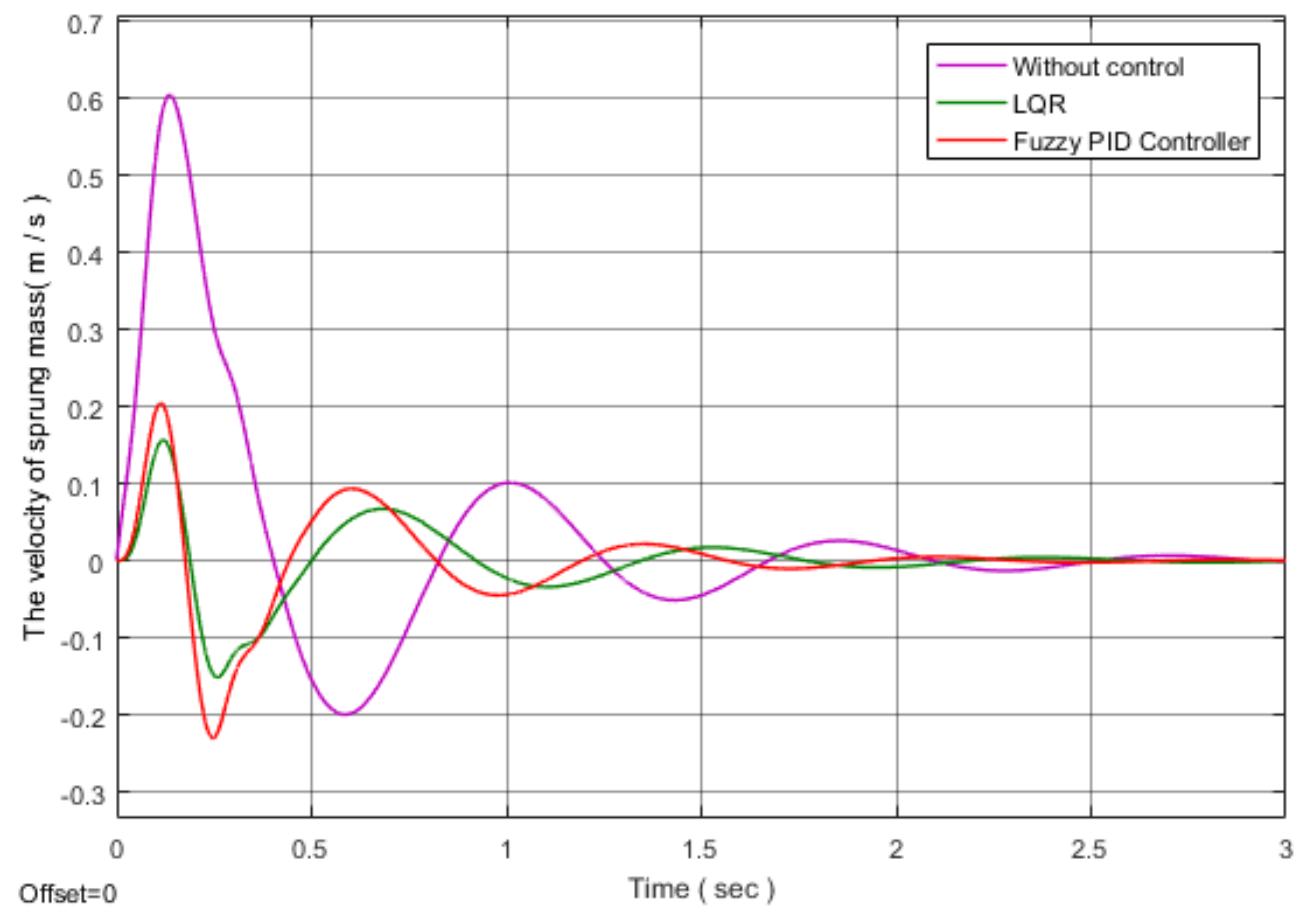

Figure 12 The velocity of sprung mass. 


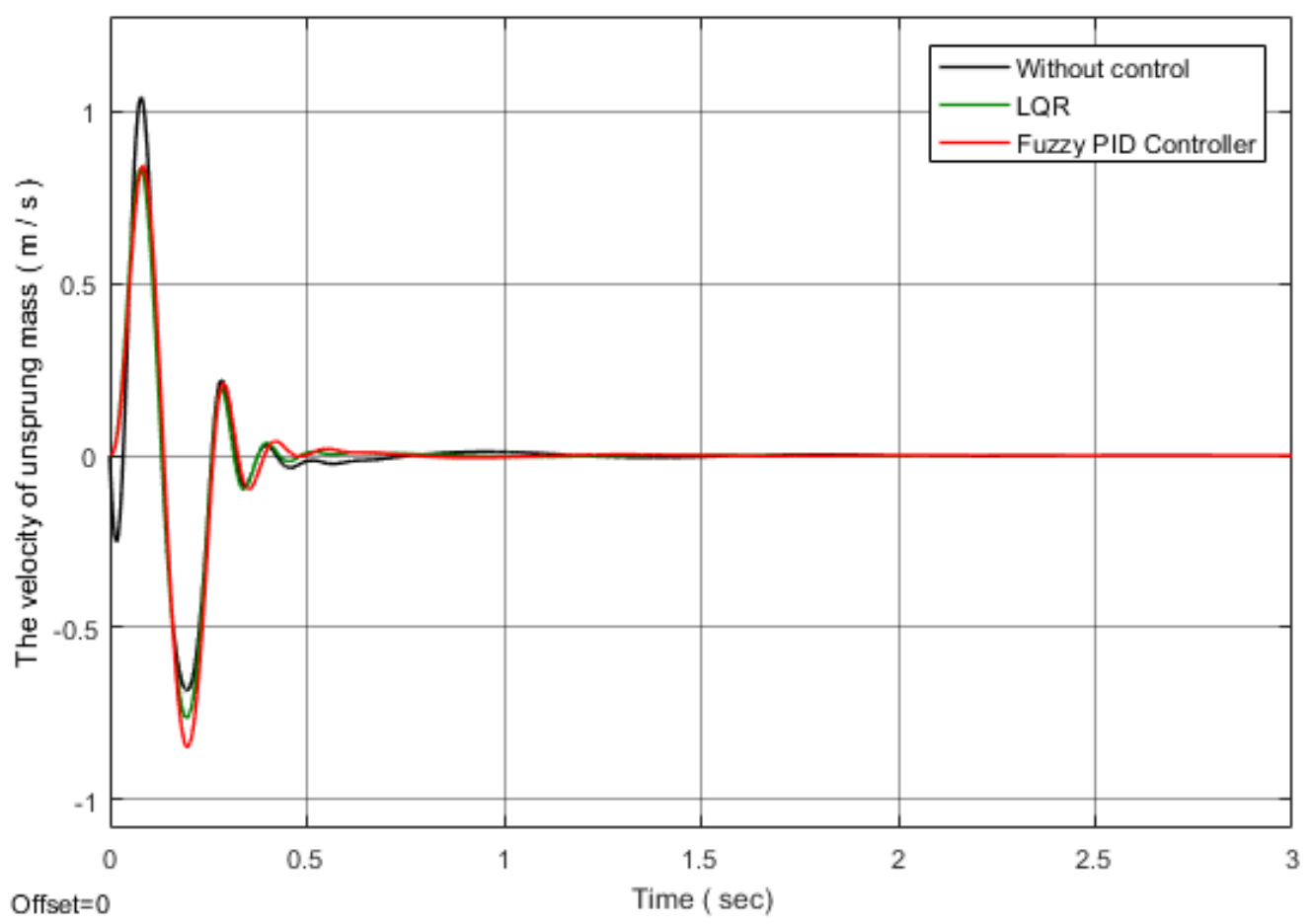

Figure 13 The velocity of unsprung mass.

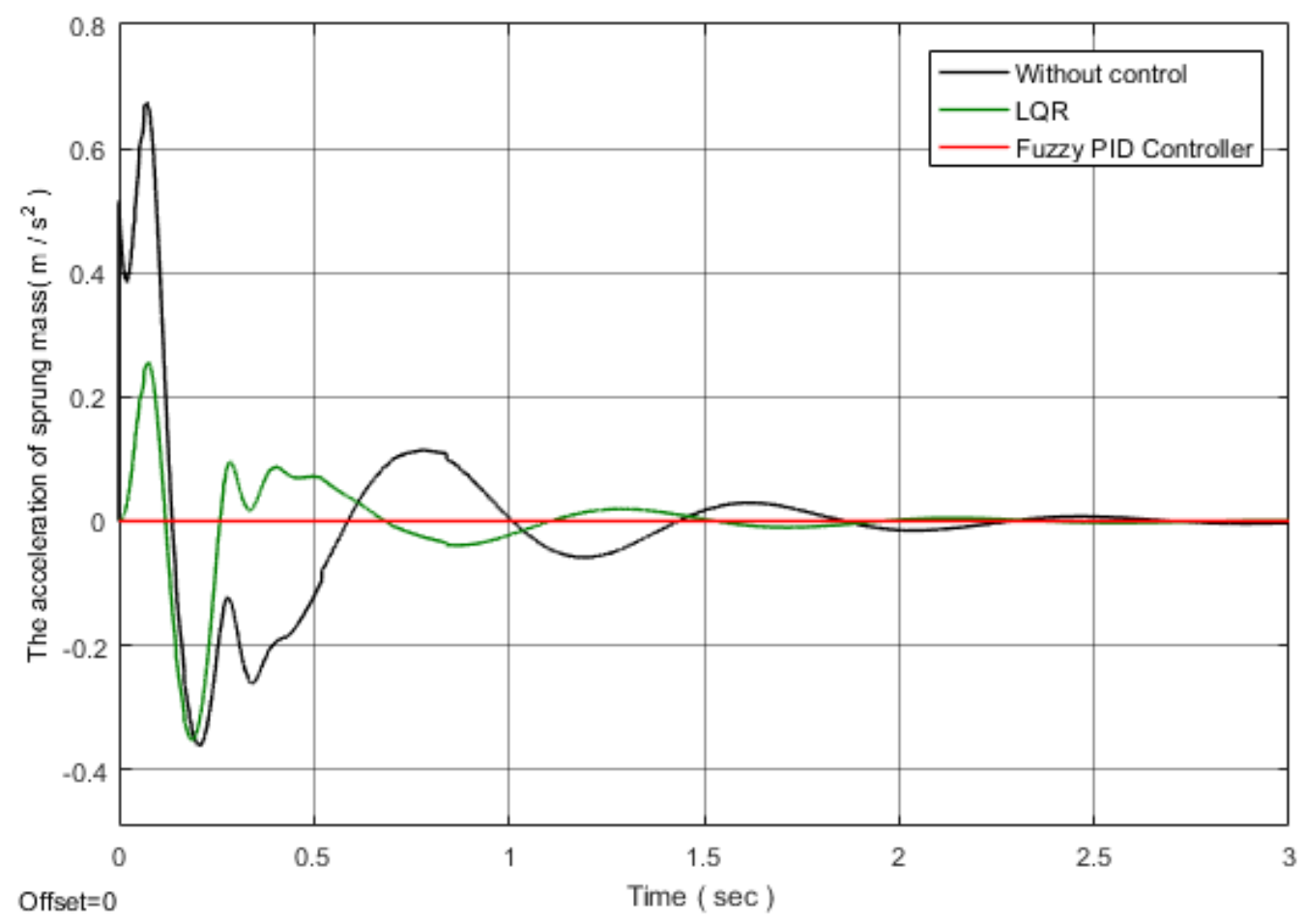

Figure 14 The acceleration of sprung mass.

\section{Results and Discussion}

Further analysis of the active suspension system is discussed by comparing the uncontrolled system with the LQR control approach and fuzzy PID control. 
Figure 10 shows a comparison response of the suspension deflection without control and with LQR and fuzzy PID controllers, while figure 11 illustrates a compression between the tire deflection that represents the road handling indication, it's obvious that using of LQR controller has less overshoot a very small settling time as compare to fuzzy PID controller.

Figures 12 and 13 show the behavior of the unsprung and sprung velocities for the quarter model. The sprung mass velocity in the LQR case has been found to reduce their value in comparison to the fuzzy PID controller case.

The acceleration of the sprung mass also improved using the two controllers as shown in figure 14, but fuzzy PID control method gives better performance, this is very evident in the acceleration curves. The sprung mass acceleration parameter is very important and it is taken into consideration when designing car suspension systems because it represents ride comfort indication.

\section{Conclusion}

The active suspension system of the car is presented in this paper. A mathematical equation of a quarter-car model is obtained, and then the system performance is examined using two control methods (fuzzy PID control and LQR). All Simulink models of the quarter model have implemented using MATLAB software. The results showed that using the LQR method and the fuzzy PID control to evaluate and control the suspension system provides good performance of the system, but it obvious that the LQR method provides better performance of the system parameters than the fuzzy PID control method.

\section{Compliance with ethical standards}

\section{Disclosure of conflict of interest}

There are no conflicts of interest

\section{References}

[1] Muhammad Aseer Khan, Muhammad Abid, Nisar Ahmed, Abdul Wadood and Herie Park 4, "Nonlinear Control Design of a Half-Car Model Using Feedback Linearization and an LQR Controller”, Appl. Sci. 2020; 10:3075.

[2] R. Rajamani,“ Vehicle dynamics and control,” Springer Science \& Business Media, 2011.

[3] Swati Gaur and Sheilza Jain, "Vibration Control of Bus Suspension System using PI and PID Controller," International Journal of Advances in Engineering Sciences, July, 2013; Vol.3 (3).

[4] D'Amato, FJ and DE Viassolo, “Fuzzy control for active suspension”, Mechatronics, 2000; vol. 10:pp.897- 920.

[5] Yao, G Z, F F Yap, G Chen, W H Li and S H Yeo, "MR damper and its application for semi-active control of vehicle suspension system”, Mechatronics, 2002; vol. 12:pp.963-973.

[6] Abdussalam Ali Ahmed and Başar Özkan, "Evaluation Of Effect Of In-Wheel Electric Motors Mass On The Active Suspension System Performance Using Linear Quadratic Regulator Control Method", International Journal of Engineering Research \& Technology (IJERT), January-2015; Vol. 4 Issue 01.

[7] Zhi-Jun Fu, Bin Li, Xiao-Bin Ning, and Wei-Dong Xie, "Online Adaptive Optimal Control of Vehicle Active Suspension Systems Using Single-Network Approximate Dynamic Programming”, Mathematical Problems in Engineering, Volume 2017.

[8] Yumna Shahid and Minxiang Wei, “Comparative Analysis of Different Model-Based Controllers Using Active Vehicle Suspension System”, Algorithms, 2020; Vol. 13: Issue 1.

[9] Hong Chen, and Kong-Hui Guo,“ Constrained $\underset{\infty}{\mathrm{H}}$ Control of Active Suspensions:An LMI Approach”, IEEE Transaction on control systems technology, May 2005; Vol. 13:No. 3,

[10] Alireza Rezaee and Mazyar Pajohesh, "Suspension System Control with Fuzzy Logic", Journal of Communications Technology, Electronics and Computer Science, 2016; Issue 6,. 